\section{El siglo del populismo}

\author{
Pierre Rosanvallon (Autor)
}

Manantial. 2020. 290 páginas.

Fernando Quesada

https://doi.org/10.46468/rsaap.15.1.R3

El libro de Pierre Rosanvallon, recientemente traducido al español, se suma a una gran cantidad de trabajos sobre el populismo, pero tiene la originalidad de ofrecer una perspectiva global, con el propósito de comprender en profundidad y también en su amplitud "el núcleo de los elementos invariantes así como las reglas de diferenciación de los casos particulares”. Su objetivo no es entender el fenómeno como un problema sino "como una forma de respuesta a los conflictos contemporáneos".

El trabajo está organizado en tres partes. La primera apunta a diseccionar "la anatomía" del populismo separando sus cinco partes constitutivas o "componentes invariantes”. El primero de estos elementos es la noción del pueblo como figura central, sustancialista, que renuncia a cualquier tipo de perspectiva relacional y de esta forma conduce al uso de narrativas antagónicas y opuestos binarios del tipo casta/pueblo, oligarquía/ pueblo y a una lógica de la política del estilo amigo/enemigo, bien/mal. Asimismo, los discursos populistas invocan una idea de pueblo-Uno que imposibilita la existencia de diferencias culturales, sociales y políticas, observables en la realidad mediante categorías sociológicas y criterios estadísticos. El pueblo como totalidad se piensa y conforma no como la suma de las partes, sino a pesar de estas.

El segundo componente invariante es una concepción directa, polarizada e inmediata de la democracia, que preten- de regenerar los mecanismos de las democracias liberales representativas. Regeneración que suele ser en muchos casos degeneración, al devenir en formas iliberales de democracia, expresadas tanto en las derechas (Viktor Orbán, Vladimir Putin) como en las izquierdas (Chantal Mouffe y Ernesto Laclau). Un rasgo común en ambos hemisferios ideológicos es su intento de eliminar cuerpos intermediarios -medios de comunicación, mecanismos de mediatización de la opinión pública y tribunales constitucionales- a los que les asignan un papel funcional, "respecto del papel de espontaneidad democrática" y moral, "fundada en la sospecha de dependencia de intereses particulares y del poder del dinero".

Otro componente que comparten los populismos es una modalidad de representación basada en la idea de hombrepueblo o "representación-espejo" que radica en el reflejo del pueblo en un líder, en la que no caben intermediarios partidarios ni grupos identificados con expresiones concretas (clases sociales, campesinos, artesanos, etcétera.).

El autor considera que el cuarto elemento es una política y una filosofía nacional-proteccionista de la economía. La nación para los populistas presupone una entidad que se ubica en un determinado espacio geopolítico que se debe proteger frente a los avances de fuerzas transnacionales e internacionales.

El quinto componente que identifica es el "régimen de pasiones y emocio- 
nes" en el que se traducen las frustraciones y decepciones de los que se autodenominan pueblo. Asimismo, esta concepción plantea antagonismos del tipo "razón tecnocrática" versus "emoción popular" y abona las condiciones de surgimiento de teorías conspirativas y de complots que le brindan sentido didáctico a sujetos a los que les resultan indescifrables los procesos, conflictos y acontecimientos históricos en los que están inmersos.

A la segunda parte del libro, Rosanvallon la denomina "Historia", en la que repasa el uso histórico de la palabra populismo y los diversos contextos en los que se utilizó la expresión. En este repaso encuentra tres grandes momentos históricos. El primero es el que ubica en la Francia de Luis Napoleón Bonaparte y sus mecanismos para establecer una democracia iliberal construida en base a plebiscitos continuos.

El segundo momento considera que es la coyuntura entre 1890 y 1914, en la que emergieron partidos como el People's Party y el Progressive Movement en Estados Unidos, país en el que estos movimientos terminaron renovando las instituciones democráticas y finalmente fueron absorbidos por el sistema democrático. El autor entiende que, en Francia durante este período, emergieron expresiones populistas con el episodio boulangista, en un contexto de frustración y rencor nacional por la derrota bélica frente a Alemania. Estos discursos luego fueron retomados por la derecha encolumnada detrás de Maurice Barrès.

En el tercer momento populista ubica al "laboratorio latinoamericano" en el que la figura del colombiano Jorge Eliécer Gaitán resultó una expresión temprana y original, pero cuyo movimiento fue abortado debido a su asesinato. También expone el caso de Juan Domingo Perón y de forma más breve la variante brasileña (Getúlio Vargas) y la mexicana (Lázaro Cárdenas).

En esta parte podemos encontrar algunas omisiones. El libro se posiciona desde una perspectiva global que no termina acometiendo, porque concluye en un gran esfuerzo por buscar expresiones, discursos y prácticas electorales del populismo en suelo francés. Por otro lado, si bien son abordados los diversos populismos de derecha y de izquierda, no menciona el caso de India y el ascendente populismo radical de Narendra Modi.

La tercera parte del libro es una crítica a la teoría democrática en la que se pretenden constituir los populismos. Los sistemas democráticos, afirma, están atravesados por "riesgos estructurales" de los que echan mano los populistas para fortalecer su poder. El "referéndum" es un asunto que ha estado en el centro de las problemáticas de las democracias modernas, porque a su entender tiene cuatro implicancias negativas para estas. En primer lugar "disuelve la noción de responsabilidad política" y difumina la "dimensión de reflexividad" que implica la construcción legislativa. En segundo, confunde las nociones de voluntad y decisión, las cuales están relacionadas con la temporalidad de los asuntos democráticos. Mientras que la primera está relacionada con políticas de mediano y largo plazo, la segunda implica el corto plazo, una forma de confundir la faz arquitectónica con la faz agonal de la política. El tercer punto que observa se refiere a la sacralización que hace del fenómeno mayoritario, al convertir a los actos públicos en irreversibles, convertirlos en "opciones binarias" por el "Sí" o por el "No" y en "opciones sustanciales". El cuarto aspecto refiere al problema de traducir en normas y leyes las opciones ga- 
nadoras, como sucedió con el Brexit. Los referéndums tienen alcances de decisión, pero no estipulan las formas de reglamentación e implementación de sus decisiones.

A modo de cierre de esta parte, subtitulada "El espíritu de una alternativa", frente al avance de los populismos Rosanvallon se interroga "¿qué alternativa proponer?”. La primera respuesta, según el autor, es "ampliar la democracia para darle cuerpo, multiplicar sus modos de expresión, procedimientos e instituciones". $\mathrm{Si}$, como sostienen los populistas, estamos ante una crisis de la democracia representativa y liberal, la salida no es, como pretenden, con formas iliberales de democracia. Rosanvallon afirma que el sistema democrático es "experimental" y esto le permite ir más allá del papel del limitado ejercicio electoral. En su concepción, los sistemas democráticos deben reforzar los vínculos entre repre- sentados y representantes a través de lo que llama "democracia interactiva", mediante la instalación de dispositivos permanentes de consulta, información y rendición de cuentas. Todo esto con el objetivo de instalar una "democracia de confianza", ya que considera que la confianza es de esas "instituciones invisibles" que es inevitable en la "era de la personalización de la democracia".

En el anexo que acompaña al libro, el autor brinda algunos elementos para profundizar la historia del concepto de populismo utilizado por diversos movimientos políticos y también por la literatura.

El libro brinda muchos elementos para comprender el populismo sin quedarse solamente en su denostación, sino con el objetivo de ampliar las reflexiones sobre el fenómeno, de manera intrincada con la democracia moderna y las lógicas irresueltas con las que carga este sistema. 